\section{Introduction}

\section{Journalology: The Study of the Dissemination of Academic Knowledge}

A journal of educational research and practice

2021 Vol. 30 (2) 1-5

https://journals.library.brocku.ca/brocked

\title{
Trevor Norris*
}

Brock University

As the number of submissions to Brock Education continue to grow, and as we continue to publish high-quality research with an increasing number of daily downloads and citations, we have gained acceptance from Scopus and the Emerging Sources Citation Index. This editor's introduction comments on the landscape of journal publishing, or "scholarly communication." Higher Education institutions depend greatly on the dissemination of scholarship and research, and academic journals are a crucial part of this process.

Journal publishing continues to evolve rapidly in new, interesting, troubling, and encouraging ways. Academic journals are increasingly the topic of study and research publication, giving rise to the aptly titled field of journalology, led by expert journalologists-terms coined at the annual Peer Review Congress (Couzin-Frankel, 2018). This nascent field diverges from areas of study such as mass communications, journalism, and media studies, among others, insofar as journals depend on peer review and the dissemination of quite specialized information not necessarily intended for general public consumption. On the other hand, journalology often intersects with those fields because many academic journals are owned by what could be called mass media organizations. Academic journals are almost educational institutions themselves, inasmuch as they "educate" scholars and the general public. Some consider this a form of "public pedagogy," in the sense that academic journals themselves serve a pedagogical function (Sandlin et al., 2011).

\section{Public Dissemination of Knowledge: Journals and Encyclopedia}

Some publishers-like London-based Pearson and Netherlands-based Elsevier-date back centuries. The first academic journal was the Philosophical Transactions of the Royal Society, first published in 1665. This is also the world's longest running scientific journal, already nearly two centuries old when Darwin first published some of his works (Royal Society, 2015). The Transactions began as the monthly publication of the meetings of the Royal Society of London

\footnotetext{
*tnorris@brocku.ca
} 
for Improving Natural Knowledge. The publication not only contributed to the advancement of scientific knowledge but also helped establish the norms for the conduct of scientific research and created the first iteration of what we would now call a "research community." In other words, from the outset, academic journals have not only disseminated information but also created research communities and perpetuated scholarly norms that govern how research is conducted. They have determined what constitutes legitimacy in the spheres of knowledge, methodology, and new directions for research.

Around the time that the Transactions were founded, the first encyclopedias emerged. Derived from the Greek enkyklios (meaning general) and paideia (meaning education), the encyclopedia aimed to offer "general education" or "complete knowledge." The first in English, titled Cyclopaedia: or, An Universal Dictionary of Arts and Sciences and published between 1728 and 1751 , amounted to some 1,100 pages. Perhaps the most famous and influential was initiated by the French encyclopédistes Diderot and d'Alembert, whose Encyclopédie, ou dictionnaire raisonné des sciences, des arts et des métiers [Encyclopedia, or a Systematic Dictionary of the Sciences, Arts, and Crafts] was published in Paris between 1751 and 1772, and consisted of some 18,000 pages of text encompassing 74,000 articles in 28 volumes from more than 130 authors.' Its aim-according to the much newer Internet Encyclopedia of Philosophy- "was to provide a complete alphabetical treatment of the whole field of human knowledge" as "no other collection of general information so large and so useful was then in existence" (“Encyclopedists," n.d., paras. 1, 3).

Topics in the Encyclopédie range from philosophy and literature to the sciences and the arts and are organized into the "taxonomy of human knowledge": Memory/History, Reason/Philosophy, and Imagination/Poetry. This organization of knowledge was as controversial as the content of the entries. Because the Encyclopédie tied knowledge to reason and evidence rather than traditional institutions, it made knowledge accessible to the average person in an unprecedented way and was met with considerable hostility from both Church and monarchy, whose former monopoly on knowledge was threatened. Publication was suspended on several occasions, many authors withdrew, and sales were banned long before the project was completed. What is perhaps most remarkable is that the Encyclopédie contributed significantly to extraordinary political change: the French Revolution (Darnton, 1984). Few publications can claim such an impact!

Some encyclopedia are general (such as Encyclopedia Britannica), while others are specialized, for example those focusing on education (such as the Oxford Research Encyclopedia of

\footnotetext{
1 The encyclopedia can be viewed via The ARTFL Encyclopédie (R. Morrissey \& G. Roe, Eds.), part of the ARTFL Project, a collaboration between the French government and the University of Chicago. See: https://encyclopedie.uchicago.edu/
} 
Education ${ }^{2}$ or the Encyclopedia of Educational Philosophy and Theory. ${ }^{3}$ If the Encyclopédie democratized knowledge by wresting its control from Church and monarchy, its modern-day descendant, Wikipedia, has taken the democratization of knowledge much further by allowing literally anybody to contribute to its collection and preservation.

In its namesake entry, Wikipedia defines itself as "a free, multilingual online encyclopedia written and maintained by a community of volunteer contributors through a model of open collaboration, using a wiki-based editing system. Wikipedia is the largest and most-read reference work in history" ("Wikipedia," 2021, para. 1). Founded in 2001, the site carries no ads and is funded mainly through donations to the Wikimedia Foundation; with more than 55 million articles in hundreds of languages, it is the 13th most popular site on the internet, with over two billion visits and 17 million edits per month ("The Other Tech Giant," 2021). Much like academic journals, encyclopedias from the Cyclopaedia to Wikipedia have contributed greatly to the dissemination of new knowledge. And, much like journals, encyclopedias do so through the creation of a "research community," whether that constitutes a small group of intellectual elites or literally anybody with an internet connection.

The emergence of academic journals and encyclopedias reflects the Enlightenment hopes founded on the liberatory power of the dissemination of knowledge beyond the Church and Royal Courts, contributing to what Immanuel Kant called the "Public Use of Reason." In a similar vein, German social theorist Jurgen Habermas writes about how the emergence of "print culture" contributes to the creation of a public sphere, or civil society, particularly when the first periodical publications with autonomy from the Church and state or monarchy began to emerge, especially those critical of both. In his influential The Structural Transformation of the Public Sphere, Habermas (1962/1991) outlines the development of distinctive "discursive spaces" that contribute to the creation of public identities and the critique of established public authorities and existing social relations.

The creators of the first encyclopedias believed in the potential of the dissemination and production of new knowledge to transform the world for the better. For example, Enlightenment thinkers such as Condorcet (1795) argued that such progress in knowledge-and its dissemination-would necessarily translate into greater freedoms, affluence, health, equality, and justice. In the 21 st century, we may not share the same optimism in human perfectibility, or certainty that eventually we can gain thorough and complete knowledge of nature and the world. By contrast, new research in our time is increasingly a mopping up operation, cleaning up the messes of the Enlightenments' excessive optimism and naivete regarding the potential contributions of research and its dissemination. Climate Change journals are a case in point.

\footnotetext{
2 Available at https://oxfordre.com/education

${ }_{3}$ Available at https://link.springer.com/referencework/10.1007/978-981-287-532-7
} 


\section{Peer Review}

Much has clearly changed since the genesis of the first journals and encyclopedias. For the modern journalologist, one pressing question is how the dissemination of new knowledge and the definition of "research community" will continue to evolve over the course of the $21 \mathrm{st}$ century. Payment for peer review may be next, already a common practice in publishing houses for reviewers of book proposals. Some argue that, because many faculty work as paid consultants, they should be paid for their reviewing labour. This is especially true, they argue, considering the high profit rates of many publishers, most of which comes from libraries at the universities where those same academics work. Advocates note that pay would motivate reviewers and address issues like "reviewer fatigue," delays in publishing, and reviews that lack depth and substance (Rennie, 2016). However, critics argue that unethical reviewing would increase and that reviewers would take on submissions outside their area of expertise. They also point out that there is no clear and consistent way to monetize a review and that establishing such a system would undermine the status of the generation of new scholarly knowledge as a public good and eliminate many less profitable journals (Wren et al., 2019). The same critics argue that there is no need to change the system since many academics see reviewing, along with a variety of other unpaid tasks, as simply a part of their paid job, even if vaguely described. While some have proposed an "article processing charge" to offset costs, this would incentivize higher acceptance rates and, if charged at the front end (submission), would exclude many scholars-and whole fields-on financial grounds alone. One journal estimates that reviewer pay would cost up to $\$ 14$ million per year and constitute the single largest expense in academic publishing (Brainard, 2021).

While the topic of payment for peer review remains open, there have been efforts to address some of the other issues created by the peer review system; for example, timely publication and reviewer anonymity. New innovations include "open peer review" on sites such as Academia, and the publication of "preprints"-publicly available articles at the point of submission to a journal that are technically not subject to the same copyright standards. Other experiments in peer review include The British Medical Journal, which disclosed names of authors and reviewers to each other during review and made the reviewers' names public if the paper was published; there was no decline in submission rates or reviewer participation (Rennie, 2016). There are ongoing studies into which method of review is most appropriate to each discipline and journal.

There are, however, many limits to the study of journals. For example, several journals refused to participate in a study about the influence of advertising within a journal on the content of articles within that journal, leading to questions about bias in the treatment of commercial interests (Couzin-Frankel, 2018). Journalologists will have to find ways around these obstacles since peer review and other mechanisms of accountability - at the heart of journalology-are even more important in an age of anti-intellectualism, fake news, and hostility towards expertise. 
Brock Education depends greatly on thorough, timely, and rigorous double-blind peer reviewsin some cases almost as substantial and thoughtful as the original submissions. These reviews advance our contribution to "public pedagogy," the "Public Use of Reason," and the generation of a scholarly community of inquiry. Journalology will have much to offer.

\section{References}

Brainard, J. (2021, March 1). The $\$ 450$ question: Should journals pay peer reviewers? Science. https://doi.org/10.1126/science.abh3175

Condorcet, M. (1795). Outlines of an historical view of the progress of the human mind. M. Carey, H. and P. Rice and Co.

Couzin-Frankel, J. (2018, September 19). "Journalologists" use scientific methods to study academic publishing. Is their work improving science? Science. https:// doi.org/ $10.1126 \% 2 F s c i e n c e . a a v 4758$

Darnton, R. (1984). Philosophers trim the tree of knowledge: The epistemological strategy of the Encyclopedie. In The great cat massacre and other episodes in French cultural history (pp. 191-213). Basic Books.

Encyclopedists. (n.d.). In Internet encyclopedia of philosophy. Retrieved July 6, 2021 , from https://iep.utm.edu/encyclop/

Habermas, J. (1991). The structural transformation of the public sphere: An inquiry into a category of bourgeois society (T. Burger \& F. Lawrence, Trans.). The MIT Press. (Original work published 1962)

The other tech giant: Wikipedia is 20 , and its reputation has never been higher. (2021, January 7). In The Economist. https://www.economist.com/international/2021/01/09/wikipediais-20-and-its-reputation-has-never-been-higher

Rennie, D. (2016). Let's make peer review scientific. Nature, 535, 31-33. https:/ / doi.org/10.1038/535031a

Royal Society. (2015). Philosophical Transactions: 350 years of publishing at the Royal Society (1665-2015). https://royalsociety.org/-/media/publishing350/publishing350exhibition-catalogue.pdf

Sandlin, J. A., O'Malley, M. P., \& Burdick, J. (2011). Mapping the complexity of public pedagogy scholarship: 1894-2010. Review of Educational Research, 81(3), 338-375. https:/ / doi.org/10.3102\%2F0034654311413395

Wikipedia. (2021, July 6). In Wikipedia. https://en.wikipedia.org/wiki/Wikipedia

Wren, J. D., Valencia, A., \& Kelso, J. (2019). Reviewer-coerced citation: Case report, update on journal policy and suggestions for future prevention. Bioinformatics, 35(18), 3217-3218. https://doi.org/10.1093/bioinformatics/btz071 